\title{
Multiple and giant coronary artery aneurysm - case report and a review of the literature
}

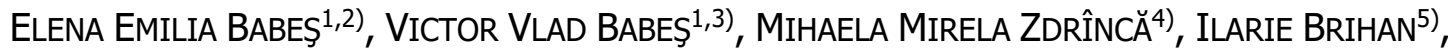 \\ RĂZVAN MARIUS VICAŞ ${ }^{6}$, MONICA AdRIANA MOTORCA ${ }^{1)}$, LARISA RENATA PANTEA-ROŞAN ${ }^{1}$, \\ ALINA CRISTIANA VENTER ${ }^{6,7)}$
}

\author{
1) Department of Medical Disciplines, Faculty of Medicine and Pharmacy, University of Oradea, Romania \\ 2) Department of Cardiology, Emergency County Hospital, Oradea, Romania \\ 3) Department of Interventional Cardiology, Emergency County Hospital, Oradea, Romania \\ 4) Department of Preclinical Disciplines, Faculty of Medicine and Pharmacy, University of Oradea, Romania \\ 5) Department of Psychoneuroscience and Rehabilitation, Faculty of Medicine and Pharmacy, University of Oradea, \\ Romania \\ 6) Department of Morphological Disciplines, Faculty of Medicine and Pharmacy, University of Oradea, Romania \\ 7) Department of Radiology, Emergency County Hospital, Oradea, Romania
}

\begin{abstract}
We report an unusual case of a 70-year-old female patient admitted in the Department of Cardiology, Emergency County Hospital, Oradea, Romania, for unstable angina and heart failure. Coronary angiography and computed tomography revealed multiple coronary artery aneurysms, some of them giant, associated with significant coronary artery disease. Coronary artery aneurysm is a rare disease, but the frequency of diagnostic increased with the development of coronary angiography. However, very rarely coronary artery aneurysm is very large and can be termed "giant aneurysm", and a small number of reports have been described in literature. The management and the prognosis of the disease is still controversial.
\end{abstract}

Keywords: coronary artery, aneurysm, giant, atherosclerosis.

\section{a Introduction}

Coronary artery aneurysm is defined as a localized dilatation of a coronary artery of saccular or fusiform shape that is larger than the diameter of the normal vessel adjacent segment by $1.5-2$ times $[1,2]$. A true arterial aneurysm can be fusiform, with the longitudinal diameter larger than the transversal diameter or saccular, with the transverse diameter larger than the longitudinal diameter. Fusiform aneurysms are much more common than saccular aneurysms.

Coronary artery ectasia is a diffuse dilatation that includes $50 \%$ or more of the length of a coronary artery [3].

Sometimes, a coronary artery aneurysm dilates very much and can be classified as giant, but the dimensions of such aneurysms are variable in literature. The Committee of the American Heart Association has defined giant aneurysm when the diameter is more than $8 \mathrm{~mm}[4,5]$, but other authors consider aneurysm to be giant when are greater than $20 \mathrm{~mm} \mathrm{[6].}$

The tunica media of the coronary aneurysms is usually thinned and can be destroyed markedly until is unidentifiable between intima and adventitia. The hyalinized connective tissue replaces the normal smooth muscle cells and elastic fibers from the middle layer of the coronary artery [7]. In pseudoaneurysms or false aneurysms, there is a rupture of the arterial wall contained by the adventitia or a blood clot.

Coronary artery aneurysm is a rare abnormality. It was first reported in 1761, on post-mortem examination, by Morgagni and by Bourgon in $1812[8,9]$. The largest autopsy series, by Daoud et al. [10], reported a $1.4 \%$ incidence of coronary artery aneurysm in 694 patients. Munkner et al. [11] presented the first case diagnosed alive with coronary angiography in 1958 . The frequency of diagnosis of coronary artery aneurysm increased with the development of coronary angiography. In Coronary Artery Surgery Study (CASS) Registry, the angiographic incidence of coronary aneurysm was $4.9 \%$ in a group of 20087 patients [12], which exceeded the incidence reported in many other angiographic studies $(0.37-2.53 \%)$ [13]. The reported prevalence of giant coronary artery aneurysm is very low $(0.02 \%)$ [14].

\section{Aim}

The aim of this study was to present a rare case of multiple coronary artery aneurysms distributed thorough the coronary system, some of them large enough to be called giant, discovered at coronary angiography.

\section{ㅁ Case presentation}

A 70-year-old woman was admitted in the Department of Cardiology, Emergency County Hospital, Oradea, Romania, in March 2010, for refractory unstable angina despite maximal medical treatment and exertional dyspnea. She had a history of previous old anterior myocardial infarction, which was managed with medical treatment in

This is an open-access article distributed under the terms of a Creative Commons Attribution-NonCommercial-ShareAlike 4.0 International Public License, which permits unrestricted use, adaptation, distribution and reproduction in any medium, non-commercially, provided the new creations are licensed under identical terms as the original work and the original work is properly cited. 
a territorial hospital (without thrombolysis) and hyperlipidemia. On physical examination, we found pulmonary stasis at the base of the lungs, peripheral edema, her blood pressure was $110 / 80 \mathrm{mmHg}$, and heart rate was 90 beats/min. Electrocardiogram showed old anterior myocardial infarction with QS waves and $2 \mathrm{~mm}$ persistent ST segment elevation in V1-V5, negative T waves V1V6, first diagonal branch-augmented vector left (D1aVL). Cardiac enzymes [creatine kinase MB isoenzyme (CK-MB) and highly sensitive troponin] were in normal range. Her blood cholesterol level was $246 \mathrm{mg} / \mathrm{dL}$, with a low-density lipoprotein (LDL)-cholesterol of $136 \mathrm{mg} / \mathrm{dL}$. The other blood tests were in normal range, including inflammatory markers. Transthoracic echocardiography revealed left ventricular apical aneurysm, with moderately depreciated left ventricular ejection fraction of $30 \%$, and mild pericardial effusion.

Coronary angiography showed a coronary aneurysm of the proximal segment of left anterior descending artery, with transversal diameter of $4 \mathrm{~mm}$ and longitudinal diameter of $5 \mathrm{~mm}$. Left anterior descending artery was completely occluded after the emergency of the D1 artery, with retrograde flow from the right coronary artery. The first diagonal artery was completely occluded after a second saccular aneurysm with transversal diameter of $5 \mathrm{~mm}$ and longitudinal diameter of $3 \mathrm{~mm}$ (Figure 1).

Left circumflex artery presents in the proximal part, before the emergency of an important obtuse branch, a giant aneurysmal dilatation with transversal diameter of $16 \mathrm{~mm}$ and longitudinal diameter of $35 \mathrm{~mm}$ (Figure 1).

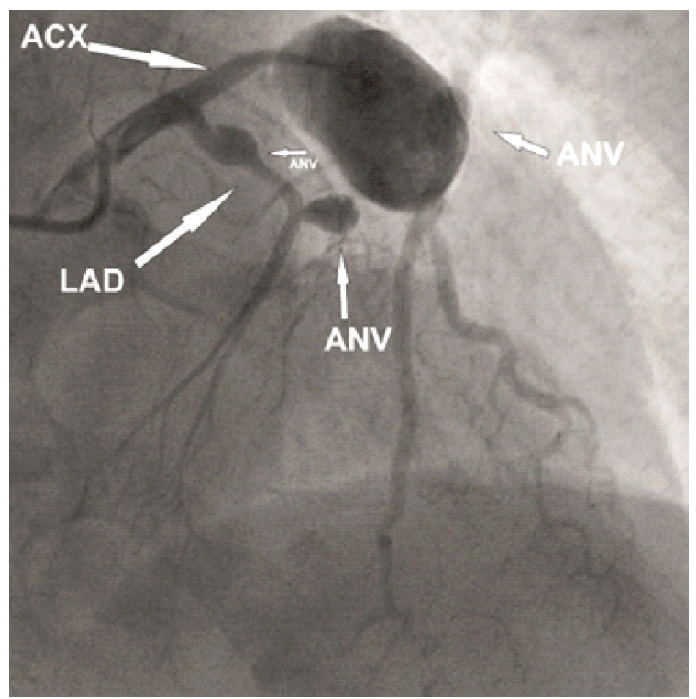

Figure 1 - Coronary angiography. Left anterior cranial view demonstrating a giant aneurysm in the proximal part of the $A C X$, with transversal diameter of $16 \mathrm{~mm}$ and longitudinal diameter of $35 \mathrm{~mm}$. LAD presents a coronary aneurysm in the proximal segment with transversal diameter of $4 \mathrm{~mm}$ and longitudinal diameter of $5 \mathrm{~mm} . \mathrm{LAD}$ is completely occluded after the emergency of the first diagonal branch. The first diagonal artery is completely occluded after a second saccular aneurysm with transversal diameter of $5 \mathrm{~mm}$ and longitudinal diameter of $3 \mathrm{~mm}$. ACX: Circumflex artery; $A N V$ : Aneurysm; LAD: Left anterior descending artery.

The right coronary artery presents in the vertical segment an aneurysmal dilatation with transversal diameter of $7.7 \mathrm{~mm}$ and longitudinal diameter of $25 \mathrm{~mm}$, followed by another aneurysmal dilatation with a transversal diameter of $5.3 \mathrm{~mm}$ and longitudinal diameter of $7 \mathrm{~mm}$ (Figure 2).

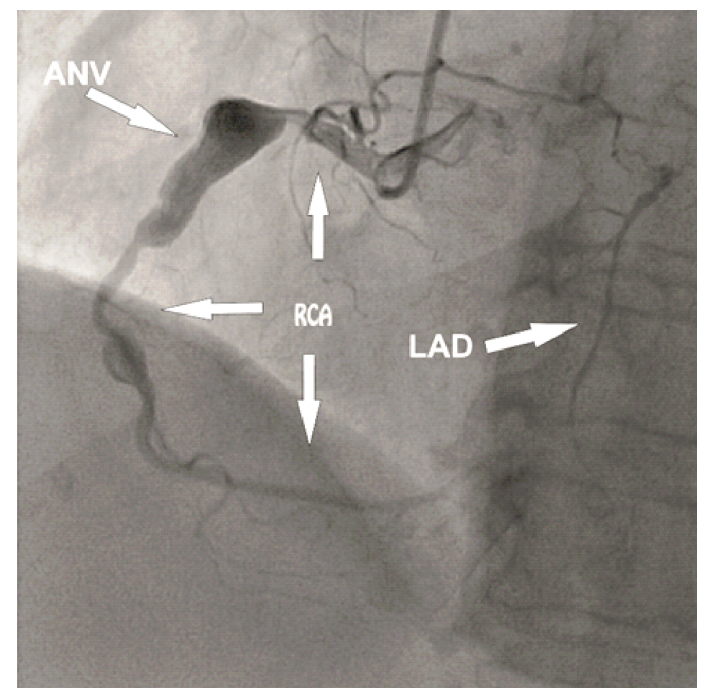

Figure 2 - Coronary angiography. Left anterior oblique view. The RCA presents in the vertical segment an aneurysmal dilatation with transversal diameter of $7.7 \mathrm{~mm}$ and longitudinal diameter of $25 \mathrm{~mm}$, followed by another aneurysmal dilatation with a transversal diameter of $5.3 \mathrm{~mm}$ and longitudinal diameter of $7 \mathrm{~mm}$. Retrograde flow from RCA to LAD. ANV: Aneurysm; LAD: Left anterior descending artery; RCA: Right coronary artery.

Cardiac computed tomography (CT) enables the further delineation of the topographical anatomy of coronary artery aneurysm. CT angiography provides a non-invasive and accurate evaluation of the localization, the dimensions and the content of thrombus or calcifications of the aneurysm. The size of the left circumflex artery aneurysm was much greater on multislice CT with contrast, the largest transversal diameter of the aneurysm was $44 \mathrm{~mm}$; but the giant aneurysm contains an important amount of thrombus on the right lateral wall of $28 \mathrm{~mm}$ (Figures 3-5). Only flow within the lumen can detected after contrast injection at coronary angiography, so the true dimensions can be undervalued if the aneurysm contains a substantial amount of thrombus as in our patient.

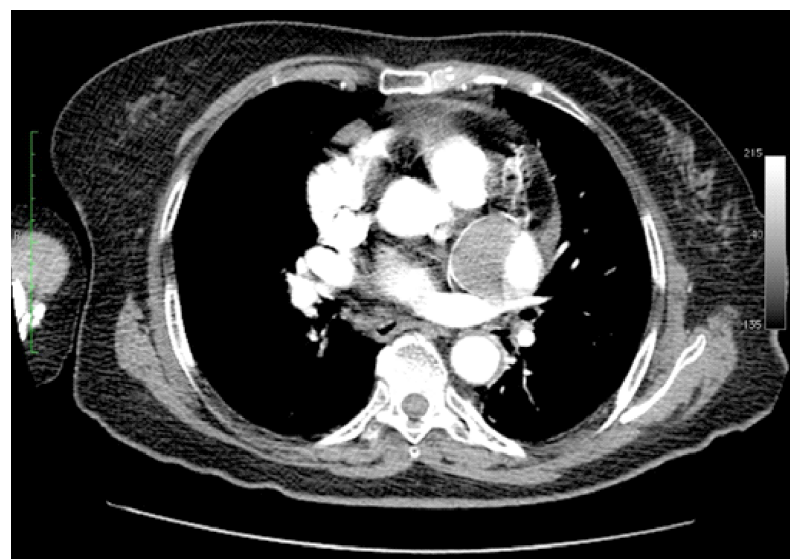

Figure 3 - Multislice computed tomography with intravenous contrast. Axial sections. Saccular giant aneurysm of the circumflex artery with the largest transversal diameter of $44 \mathrm{~mm}$ and a filling defect on the right lateral wall of $28 \mathrm{~mm}$ (thrombus), and calcification of the aneurysmal wall. 


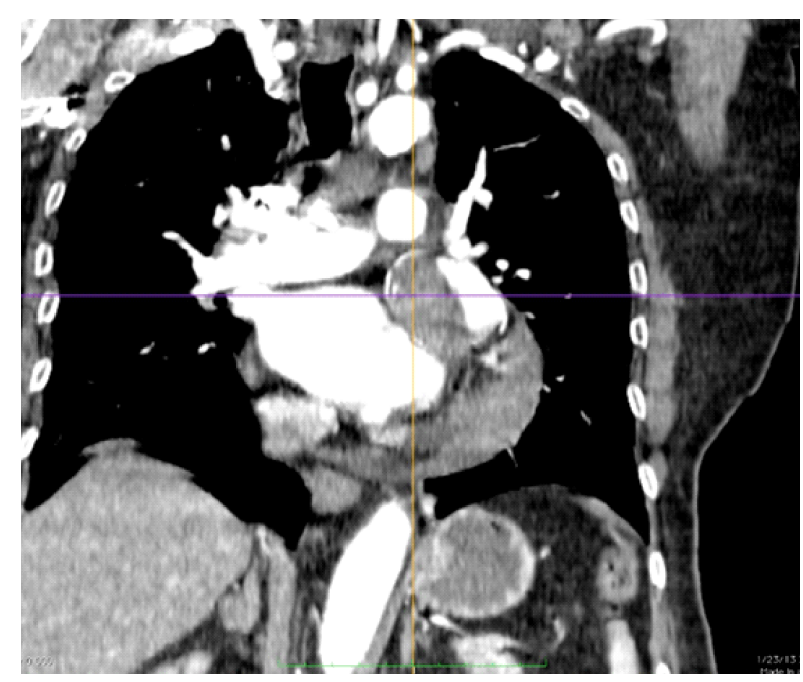

Figure 4 -Multislice computed tomography with intravenous contrast. Coronal multiplanar reconstruction. Giant aneurysm of the circumflex coronary artery with an important amount thrombus.

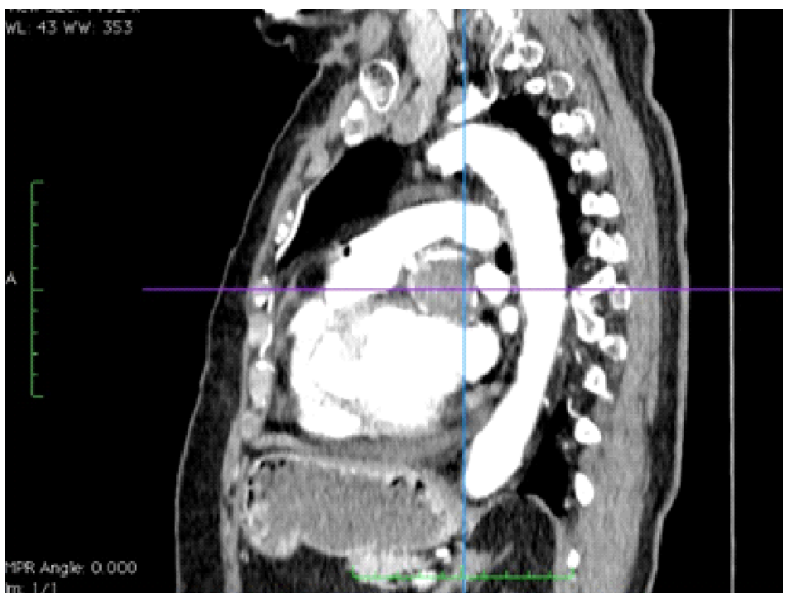

Figure 5 - Multislice computed tomography with contrast. Sagittal multiplanar reconstruction. Giant aneurysm of the left circumflex coronary artery with thrombus.

The optimal management in this patient was established to be cardiac surgery, since patient had a giant circumflex artery aneurysm, multiple other coronary artery aneurysms, which were coexisting with significant coronary artery disease, respectively occlusion of the left anterior descending artery and of the D1 artery.

The patient refused surgical treatment and was treated only with medical therapy. She received anticoagulants, antiplatelet agents, angiotensin converting enzyme inhibitors, beta-blockers, statins, and diuretics. She was discharged after nine days with improved medical condition, chest pain diminished, electrocardiogram was stable, and the markers of myocardial necrosis were not elevated.

Long-term evolution was unfavorable, she was admitted repeatedly for angina and she died after one year.

\section{Consent}

Written informed consent was obtained from the patient for invasive coronarography examination in accordance with the investigation protocol and also for the publication of this case report. No data that revealed the patient identity were presented in the manuscript.

\section{ค Discussions}

The overall incidence of coronary artery aneurysm ranges from $0.3 \%$ to $5.3 \%$, with a mean incidence of $1.65 \%$ [15], but giant artery aneurysms are very rare, with a reported prevalence of $0.02 \%$ [14]. The incidence of coronary artery aneurysm is higher in men [13], and although coronary artery aneurysm can occur at any age, those with atherosclerotic etiology appear later in life [15]. Most frequently is involved the right coronary artery $(40.4 \%)$, followed by the left anterior descending artery $(32.3 \%)$ and by the left circumflex artery $(23.4 \%)$. Left main artery is rarely involved (3.5\%) [6].

Our illustrative case had multiple coronary aneurysms on all three major coronary arteries: right coronary, left anterior descending and circumflex artery with a giant aneurysm on the circumflex artery.

The major characteristics revealed by histological examination consists of lipid deposition of the intima, alongside hyalinization deposits, intramural hemorrhage and an inflammatory reaction which reflects the intensity of the arteriosclerotic process. The chronic overstimulation of the nitric oxide represents an important factor which alters the medial layer of the vessel wall [6]. Other pathological mechanisms, which affect the elasticity of the vessel wall, consists in the presence of different areas of fibrosis, calcification, and the existence of large cholesterol crystals. All these factors contribute to the aneurysm formation. The atherosclerotic disease further affects the wall structure in the context of transmural inflammation $[8,16]$. Due to the continuous intraluminal pressure, the stress tolerance is reduced, determining dilation of the vessel wall.

It is supposed to exist a genetic contribution in atherosclerotic coronary artery disease associated coronary artery aneurysm. This was proved in some genomic-wide association studies, which reflected the connection between different variants on chromosome 9p21.3 and coronary artery disease. This specific locus may also play a role in the formation of intracranial and abdominal aortic aneurysm. Apparently, it determines an altered proliferative phenotype, which causes adverse vascular remodeling [17].

Thrombosis is common in giant aneurysm, and an important amount of thrombus was present on the right lateral wall of the giant circumflex artery aneurysm, in our patient. The internal surface of the aneurysmal wall is irregular and predispose to slow blood flow, thrombus formation and subsequent embolization.

Daoud et al. observed, in a postmortem study, the presence of thrombus in seven of 10 patients with coronary aneurysms [10]. The clinical presentation of our patient can be associated with the presence of thrombus and possible distal embolization, but we must consider that our patient had also significant coronary artery with occlusion of two coronary arteries. In our patient, the true size of the aneurysm was much greater as revealed on angio-CT, explained by the fact that the giant aneurysm contains an important amount of thrombus.

Coronary angiography is a "luminogram" that does not provide information about the wall of the vessel and can underestimate the true size of the aneurysm or can overlook an aneurysm occluded by a large thrombus or 
plaque [15]. The study performed by Murthy et al. also observed that true size of the aneurysm with thrombus content can be undervalued [18]. CT angiography is a noninvasive investigation that can accurately assess the aneurysm dimensions and location and provide information about thrombus content and calcification. The extent of thrombus compared to luminal flow is also described with confidence [18].

\section{a Conclusions}

Giant coronary artery aneurysm is a rare disease with diverse clinical symptoms that can rise problems of differential diagnosis with various disease. The management remains a clinical challenge and should be individualized for each patient considering: clinical presentation, etiology and aneurysm size, location and its expansion in time, comorbidities, the presence and extent of associated atherosclerosis.

\section{Conflict of interests}

The authors declare that they have no conflict of interests.

\section{References}

[1] Falsetti HL, Carrol RJ. Coronary artery aneurysm. A review of the literature with a report of 11 new cases. Chest, 1976, 69(5):630-636. https://doi.org/10.1378/chest.69.5.630 PMID: 1083790

[2] Swaye PS, Fisher LD, Litwin P, Vignola PA, Judkins MP, Kemp HG, Mudd JG, Gosselin AJ. Aneurysmal coronary artery disease. Circulation, 1983, 67(1):134-138. https://doi. org/10.1161/01.cir.67.1.134 PMID: 6847792

[3] Markis JE, Joffe CD, Cohn PF, Feen DJ, Herman MV, Gorlin R. Clinical significance of coronary arterial ectasia. Am J Cardiol, 1976, 37(2):217-222. https://doi.org/10.1016/ 0002-9149(76)90315-5 PMID: 1108631

[4] Mata KM, Fernandes CR, Floriano EM, Martins AP, Rossi MA, Ramos SG. Chapter 21: Coronary artery aneurysms: an update. In: Lakshmanadoss $U$ (ed). Novel strategies in ischemic heart disease. IntechOpen, 2012, 381-404. https://doi.org/10.5772/ 32331

[5] EIGuindy MS, EIGuindy AM. Aneurysmal coronary artery disease: an overview. Glob Cardiol Sci Pract, 2017, 2017(3): e201726. https://doi.org/10.21542/gcsp.2017.26 PMID: 29564347 PMCID: PMC5856968
[6] Mora B, Urbanek B, Loewe C, Grimm M, Dworschak M. Position dependent right ventricular dysfunction caused by a giant right coronary artery aneurysm. Wien Klin Wochenschr, 2011, 123(1-2):58-60. https://doi.org/10.1007/s00508-0101516-9 PMID: 21253776

[7] Syed M, Lesch M. Coronary artery aneurysm: a review. Prog Cardiovasc Dis, 1997, 40(1):77-84. https://doi.org/10. 1016/s0033-0620(97)80024-2 PMID: 9247557

[8] Robinson FC. Aneurysms of the coronary arteries. Am Heart J, 1985, 109(1):129-135. https://doi.org/10.1016/0002 -8703(85)90425-9 PMID: 3880989

[9] Scott DH. Aneurysm of the coronary arteries. Am Heart J, 1948, 36(3):403-421. https://doi.org/10.1016/0002-8703(48) 90337-8 PMID: 18880707

[10] Daoud AS, Pankin D, Tulgan H, Florentin RA. Aneurysms of the coronary artery. Report of ten cases and review of literature. Am J Cardiol, 1963, 11(2):228-237. https://doi.org/ 10.1016/0002-9149(63)90064-x PMID: 14025069

[11] Munkner T, Petersen O, Vesterdal J. Congenital aneurysm of the coronary artery with an arteriovenous fistula. Acta Radiol, 1958, 50(4):333-340. https://doi.org/10.3109/000169258091 72312 PMID: 13605871

[12] Robertson T, Fisher L. Prognostic significance of coronary artery aneurysm and ectasia in the Coronary Artery Surgery Study (CASS) Registry. Prog Clin Biol Res, 1987, 250:325339. PMID: 3423046

[13] Hartnell GG, Parnell BM, Pridie RB. Coronary artery ectasia: its prevalence and clinical significance in 4993 patients. $\mathrm{Br}$ Heart J, 1985, 54(4):392-395. https://doi.org/10.1136/hrt.54. 4.392 PMID: 4052280 PMCID: PMC481917

[14] Li D, Wu Q, Sun L, Song Y, Wang W, Pan S, Luo G, Liu Y, Qi Z, Tao T, Sun JZ, Hu S. Surgical treatment of giant coronary artery aneurysm. J Thorac Cardiovasc Surg, 2005, 130(3): 817-821. https://doi.org/10.1016/j.jtcvs.2005.04.004 PMID: 16153934

[15] Abou Sherif S, Ozden Tok O, Taşköylü Ö, Goktekin O, Kilic ID. Coronary artery aneurysms: a review of the epidemiology, pathophysiology, diagnosis, and treatment. Front Cardiovasc Med, 2017, 4:24. https://doi.org/10.3389/fcvm.2017.00024 PMID: 28529940 PMCID: PMC5418231

[16] Nichols L, Lagana S, Parwani A. Coronary artery aneurysm: a review and hypothesis regarding etiology. Arch Pathol Lab Med, 2008, 132(5):823-828. https://doi.org/10.1043/1543-21 65(2008)132[823:CAAARA]2.0.CO;2 PMID: 18466032

[17] Ozaki K, Tanaka T. Molecular genetics of coronary artery disease. J Hum Genet, 2016, 61(1):71-77. https://doi.org/ 10.1038/jhg.2015.70 PMID: 26134515

[18] Murthy PA, Mohammed TL, Read K, Gilkeson RC, White CS. MDCT of coronary artery aneurysms. AJR Am J Roentgenol, 2005, 184(3 Suppl):S19-S20. https://doi.org/10.2214/ajr.184. 3_supplement.01840s19 PMID: 15728009

\section{Corresponding authors}

Elena Emilia Babeş, Lecturer, MD, PhD, Department of Cardiology, Emergency County Hospital, 65 Gheorghe Doja Street, 410169 Oradea, Romania; Phone +40259-211 345, e-mail: babes.emilia@gmail.com

Victor Vlad Babeş, Assistant Professor, MD, PhD, Department of Interventional Cardiology, Emergency County Hospital, 65 Gheorghe Doja Street, 410169 Oradea, Romania; Phone +40259-211 345, e-mail: babesvlad@gmail.com 